\title{
WEAR ANALYSIS OF RICE HUSK PARTICULATE REINFORCED BIOMATERIAL
}

\author{
DR. ATHIMOOLAM ${ }^{1}$, M. KARTHIKEYAN ${ }^{2} \&$ BHARATHI $^{3}$ \\ ${ }^{1}$ Associate Professor, Agni College of Technology, Anna University, Chennai, Tamil Nadu, India \\ ${ }^{2,3}$ Assistant Professor, Agni College of Technology, Anna University, Chennai, Tamil Nadu, India
}

\begin{abstract}
This study deals with the wear properties of multiphase material of Polyester resin hybrid composites reinforced with particulates of rice husk. The investigation of wear response of those composites is carried out in addition to a comparative analysis between the untreated and treated rice husk particle reinforced composites. The wear and tear experiments are planned as per the DOE approach and conducted using Pin-on disc apparatus. The Pin-on disc method is used to find out the value of the parameter in optimum settings which result in the minimum wear and tear rate. The values calculated from the mathematical model is compared with the experimental values are found to be in good agreement with each other. The review of the mechanical properties and wear performance of Polyester based hybrid composites with rice husk powder reinforcement in several weight proportions. It is observed that the treated rice husk powder produces improved properties of the COF and wear resistance.
\end{abstract}

KEYWORDS: Polyester, Wear, Coefficient of Friction, Temperature \& Rice Husk

Received: Apr 27, 2020; Accepted: May 18, 2020; Published: Jun 23, 2020; Paper Id.: IJMPERDAUG202012

\section{INTRODUCTION}

The effect of filler volume fraction of rice- husk particles on the wear of Epoxy is investigated by Kandula Mahesh et al. (2019). It is found that $20 \%$ reinforcement of rice husk produces better wear properties for the developed Epoxy composites.[1] The influence of rice- husk ash(RHA) on the tribological behavior of Aluminium composites are studied and it is observed using an ANN tool that the wear behavior is improved by 20 to $40 \%$.[2]

The addition of Rice husk increased the resistance to wear of the AA6061 Aluminium matrix composites. The damage produced on the worn-out surface is also reduced. [3] Recent advances in natural fibres have attracted substantial importance as possible reinforcement in structural material. The attractive plus point of natural fibres in fabric usage has made its availability more demanding. Keeping this insight Kuruvilla Joseph et al. [4] has developed the polyester resin composite using bagasse fibre as reinforcement. The wear and other performances with reference to mechanical properties is studied. Murali Mohan Rao [5] et al. studied the tensile properties, flexural behaviour and dielectric characteristics of Wakka fibre reinforcement in a polyester resin composites. The mechanical properties of those composites are studied and compared with sisal fibre reinforced composites, banana fiber and bamboo fibre reinforced composites made under identical conditions. Researchers have started working on bio composites based on natural resin or synthetic resin, with natural fibres reinforcement. Narendra Reddy et al. [6] emphasized the demand for new bio-composites which are environmentally friendly and also decrease the price of using traditional fibres.

Klaus Friedrich et al. [7] used a scanning electron microscope (SEM) and an atomic force microscope (AFM) to study about the Epoxy based composite surfaces. They observed that the rate of specific wear including 
the fretting wear decreases with increase in the value of short carbon fibres volume content in the given sample length. When the size of the fibres decreases the resistance to wear increases in polymers composites at low filler content. Tribological performances of Epoxy composites reinforced with different particles along with short carbon fibres in different proportions were studied under various conditions of sliding and qualitative correlations were developed for the wear with respect to time. Two possible effects of nanoparticles namely, nanoscale polishing and rolling effect contributes to the reduction of the frictional coefficient of these nanocomposites. The reinforcement caused the reduction in the temperature in contact under different conditions of the test. Therefore, the related shear stresses were reduced.

Padma Priya et al. [8] have developed Epoxy laminates with waste silk fabric reinforcement. These composites possess good mechanical properties such as durability and flexural strength. The bonding at the interface of these composites gives good chemical resistance against acids, alkalis, and solvents. Hasim et al. [9] performed the wear tests on a block on shaft method employing lathe on a set-up. The glass fabric-reinforced composite reinforcement produced extremely small wear loss, and is caused mainly because of matrix loss. The wear and tear of polymer composites and friction behaviour are taken into account .These values are a function of sliding velocity, load and distance. The surface temperature plays a very important role within the frictional behaviour of the material and wear of these composites. A rise in the intensity of wear occurs because of thermal softening. The wear intensity decreases with an increase in the softening layer thickness. Here, polymer composites are operated at relatively high environmental temperature. Natural fibres possess properties like lightweight and high specific properties [10]. These fibres are available at low cost as they are extracted from highly renewable resources and with the convenience of processing which successively reducing the dependency on petroleum oil.

It is observed from the available literature, that the hybrid composite prepared using natural and synthetic fibres are found to be a possible source of replacement for conventional polymer composite. Since they can be utilised for the various application, its wear properties become important. Also, not much work carried out using most used Engineering plastics such as polyester and hence this work focuses on fabricating the rice husk reinforced hybrid polyester composites by varying the proposition of rice husk particles. The prepared composites are tested for the wear behaviour by varying the load and speed parameters.

\section{MATERIALS AND METHODS}

\section{Materials}

A polyester resin which is commercially available is used as a base matrix material for this study. This resin is cured by a polyamine hardener. Rice husk powder was selected as traditional reinforcements. Polyester resin procured from Sakthi enterprises, Private Ltd., Chennai is used for this work. Rice husk was obtained from the Hybrid laminates, Chennai was characterized and the hand lay-up method is used for the fabrication of these composites. The densities of Polyester resin used for this work have $1.1 \mathrm{gm} / \mathrm{cm} 3$. The recommended low-temperature polyester resin and the proportions of catalysts are ranging between $1 \%$ and $4 \%$ of resin weight, depending on die type of the catalyst. The proportion of catalyst was chosen on a $2 \%$ scale. A wooden mould of dimension $(300 \times 300 \times 10) \mathrm{mm}$ is used for making the composite materials specimen. The inner side of the mould is coated with a layer of gel. The easy removal of the composite material is ensured by the mould release spray used. The hand lay-up method was used to manufacture the composite material sheet with 10 $\mathrm{mm}$ thickness under room temperature conditions. Composite plates with and without reinforcement are made with same dimensions for comparing the properties. The composite material specimens are prepared by following ASTM standards 
for erosion studies.

\section{Methodology of Fabrication}

Mould prepared by using glass plates. Rice husk is dried, and mat form in $300 \times 300 \times 10 \mathrm{~mm}$ length was cut. As per weight fraction of the filler, the resin is weighed. Polyester resin is mixed well with hardener under the conditions of room temperature as per the required ratio. After applying the release agent, the mould is dried in sunlight for a few minutes. Filler and polyester resin are mixed thoroughly under room temperature conditions. The mixture consisting of rice husk filler and Polyester resin is poured inside the mould uniformly and the excess material was removed. The roller is used for doing levelling and then the curing process is being done for 8 hours in the closed mould. The material in the mould is pressed uniformly under room temperature conditions while curing is done. The test specimens are cut according to the ASTM Standards for performing wear test.

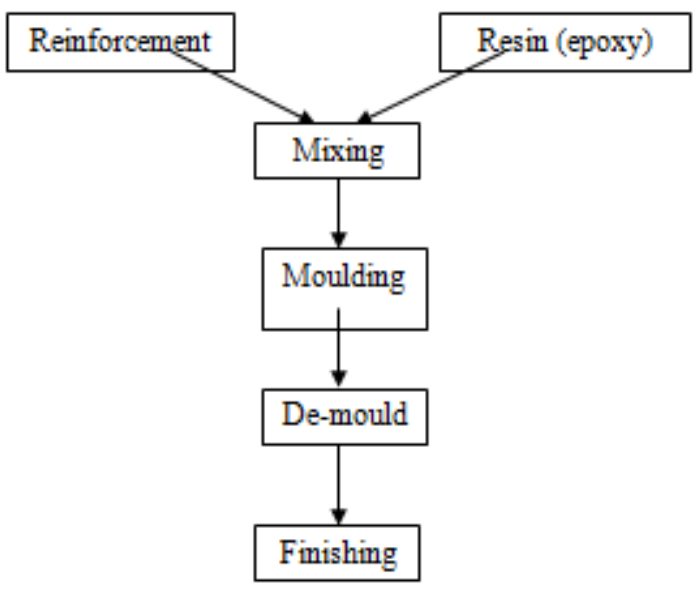

Figure 1: Steps in Fabrication of Composites.

Initially, rice husk filler is weighed separately before preparing the specimen. The required composite is then made ready, consisting of chopped where the whole net weight is measured.

Table 1: Polyester Composite Volume Fraction

\begin{tabular}{|c|c|c|}
\hline Volume Fraction of Rice Husk \% & Total Volume of Fibre (mm3) & Volume of the Matrix in \% \\
\hline $10 \%$ & 27000 & $90 \%$ \\
\hline $20 \%$ & 27000 & $80 \%$ \\
\hline $30 \%$ & 27000 & $70 \%$ \\
\hline
\end{tabular}






Preparation of mould

(a)

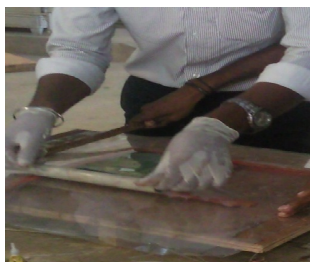

Removal of air bubbles

(d)

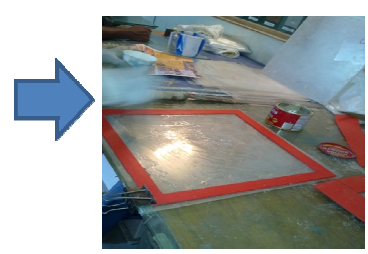

Applying resin to mold

(b)

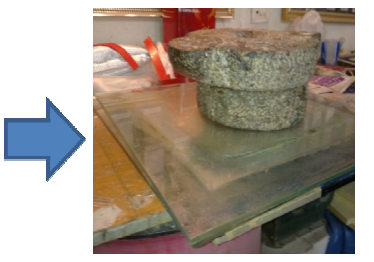

Keep weight to compress

(e)

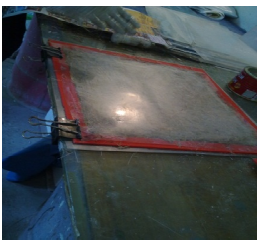

Placing the laminar film

(c)

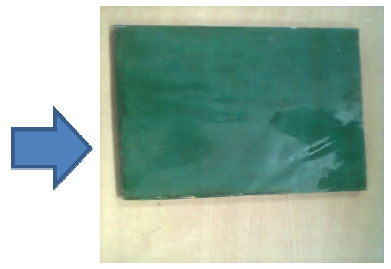

Finished composite

(f)

Figure 2: Fabrication of Composite by Hand Layup Method.

\section{Wear Test}

The composite specimens prepared by following the ASTM D3702 specifications are used for conducting wear test on a pin on disc apparatus shown in Figure 6. The pin developed was rotated on a disc with a standard dimensions adoptable for the test. The initial value of surface roughness is noted. All tests are carried out under room temperature for 5 hours duration in the dry conditions. A displacement sensor is used for measuring the reduction in the height of the specimen. A thermocouple made of iron-constantan, located on the edge of the disc is used to monitor the temperature in the disc. The ratio between the tangential force and the normal load is calculated to compute frictional coefficient and it was recorded. The specimen is weighed at the end of wear test. Then the specific rate of wear is computed by using the following relation,

$$
\mathrm{Ws}=\Delta \mathrm{m} / \rho \cdot \mathrm{t} \cdot V_{S} \cdot F_{\mathrm{N}}\left(\mathrm{mm}^{3} / \mathrm{Nm}\right)
$$

in which $F_{\mathrm{N}}$ is the load applied normal to the specimen while sliding, $\Delta m$ mass loss of the specimen, $\rho$ density of material of the specimen, $V_{S}$ is the speed and ' $\mathrm{t}$ ' is used to denote time. Here the wear rate is calculated by using the relation,

$\mathrm{Wr}=\Delta \mathrm{m} / 2 \Pi . r . n . t$

where, $\Delta m$ is the mass loss of the specimen, ' $\mathrm{n}$ ' is sliding speed and ' $\mathrm{t}$ ' is time.



Figure 3: Wear Test Specimen. 


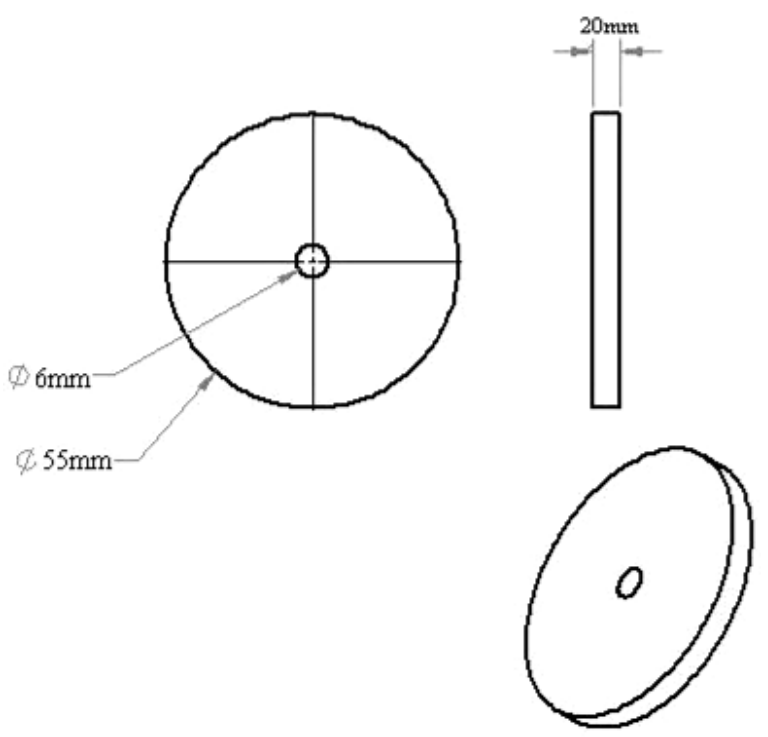

Figure 4: Dimension of Wear Testing Specimen (ASTM).

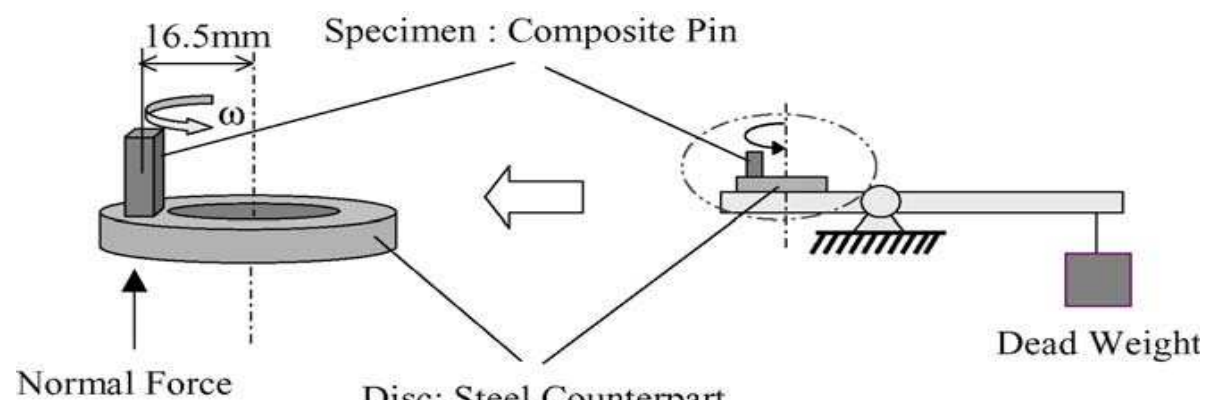

Normal Force

Disc: Steel Counterpart

Figure 5: Schematic Diagrams of the Pin on Disc (POD) Test Setup.

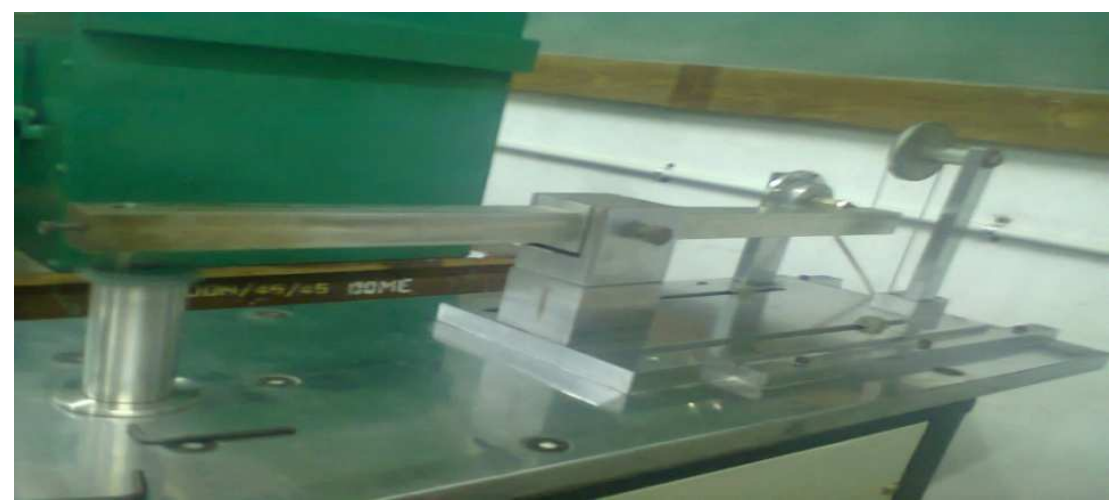

Figure 6: Wear Test on POD Apparatus.

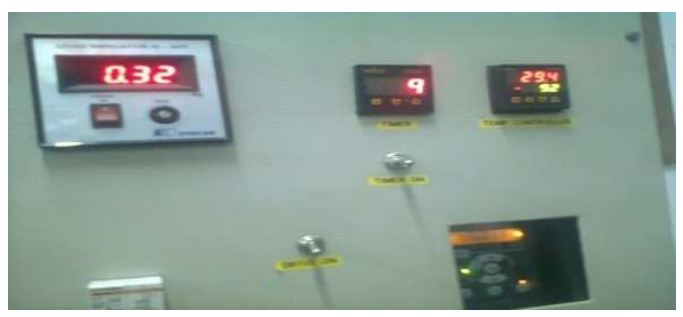

Figure 7: Control unit of POD Apparatus.

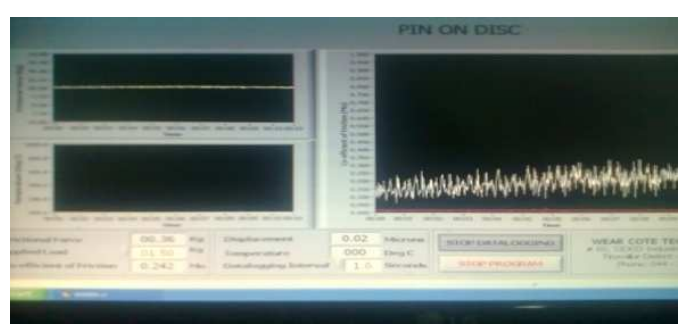

Figure 8: Output Display of POD Apparatus. 
Table 2: Process Parameters for Wear Test

\begin{tabular}{|c|c|c|} 
Load (kg) & Speed (rpm) & Time (sec) \\
\hline 0.5 & 500 & 300 \\
\hline 1 & 500 & 600 \\
\hline 1.5 & 500 & 900 \\
\hline
\end{tabular}

The process parameter for both compositions of the composite is tested during the experiment.

\section{RESULTS AND DISCUSSIONS}

The composite specimens are prepared using hand layup technique. There are 6 specimens produced out of which 3 specimens are made of $10 \%, 20 \%, 30 \%$ reinforcement of treated rice husk powder and another 3 samples are made with untreated rice husk powder reinforced in the polyester resin. The fabricated specimens are cut according to the ASTM specification standards for the wear test. The prepared composite specimens are tested in pin on disc apparatus by varying load and speed parameters to find out the wear loss, COF and frictional force.

At a time of $60 \mathrm{sec}$, upon varying the load \& speed the corresponding graph was drawn below and shown in figure 9 to figure 11. The coefficient of friction and frictional force values noted from the experimental setup are tabulated. The developed composite materials are processed and planned to study the wear properties by varying Load, Speed and Time.

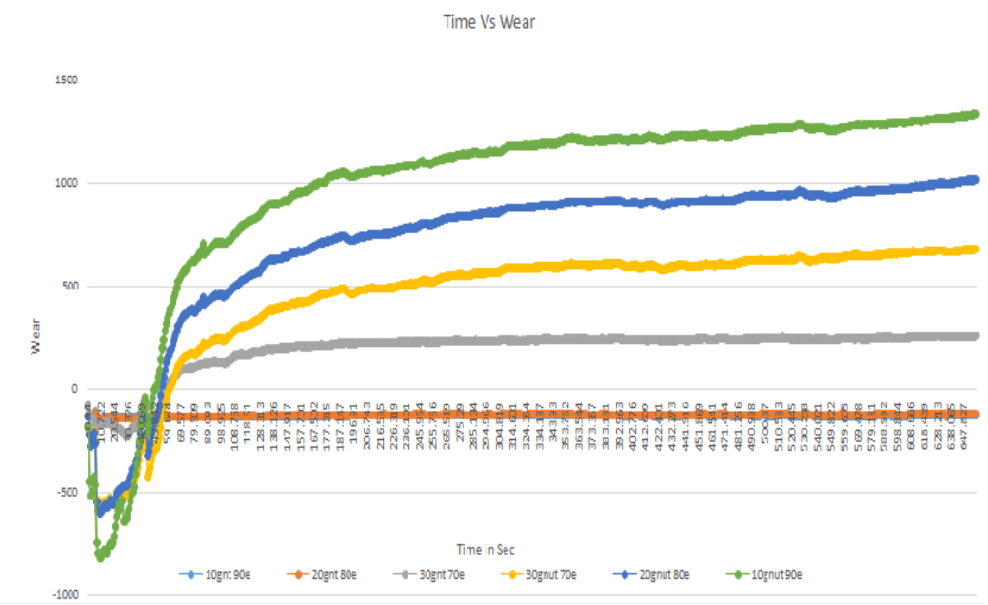

Figure 9: Time Vs Wear.

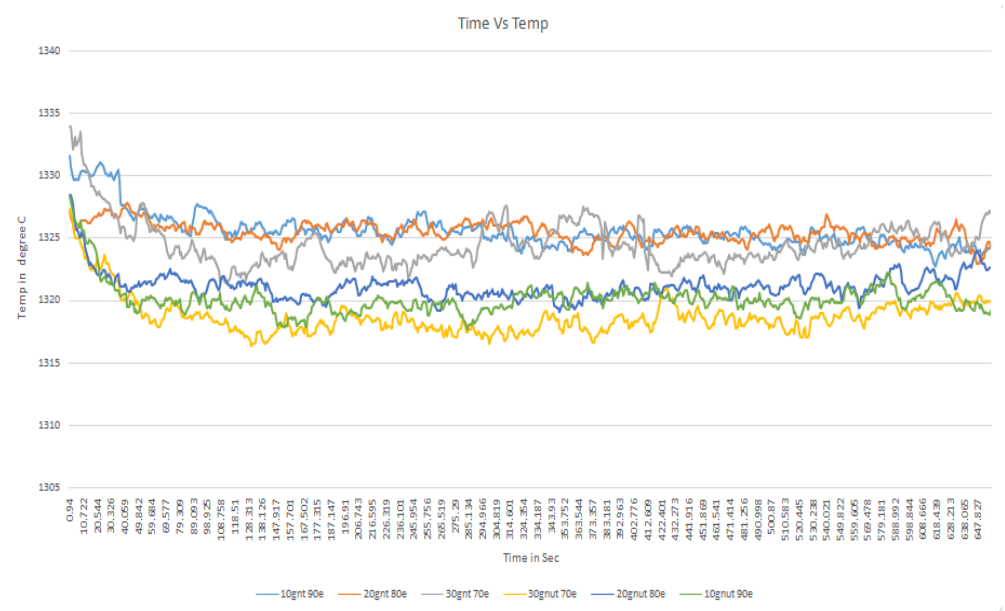

Figure 10: Time Vs Temperature. 


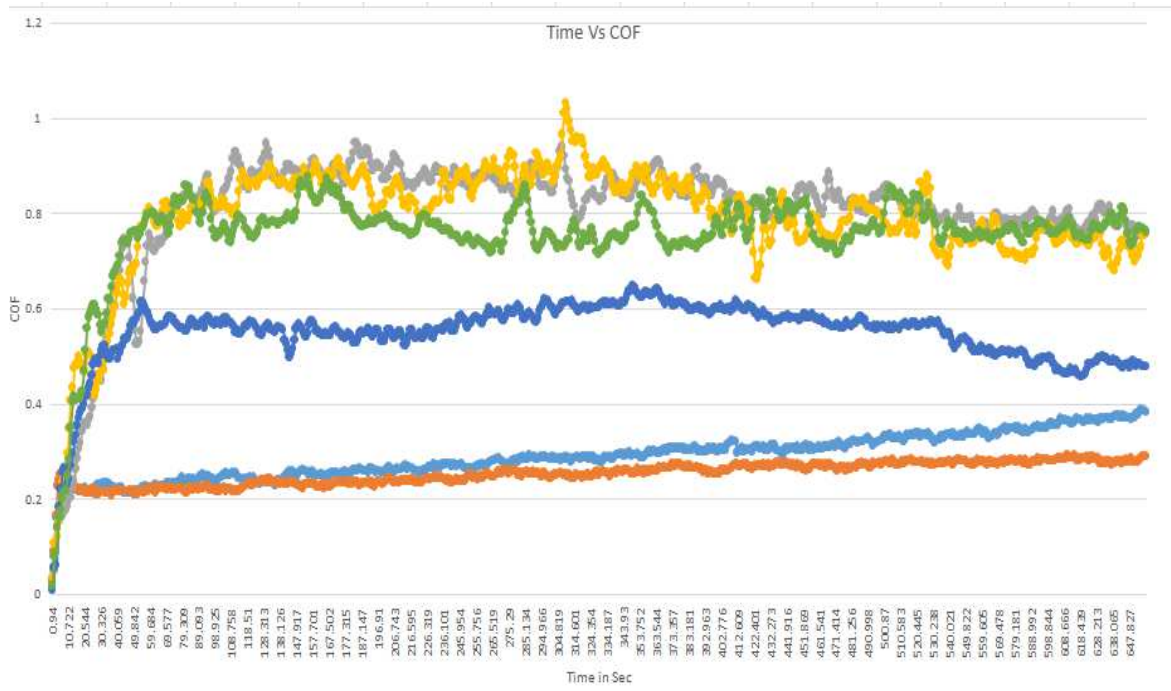

Figure 11: Time Vs Coefficient of Friction.

The rate of specific wear for a treated and untreated rice husk powder at $10 \%, 20 \%, 30 \%$ composition is calculated below. An example calculation is given below.

$\mathrm{Ws}=\Delta \mathrm{m} / \rho \cdot \mathrm{t} \cdot V_{S \cdot} F_{\mathrm{N}}\left(\mathrm{mm}^{3} / \mathrm{Nm}\right)$

$\rho=$ mass $/$ volume

$\mathrm{V}_{\mathrm{S}}=$ П.D.N

Density of the specimen;

$\rho=0.002 /(300 \times 10)$

$=0.67 \times 10^{-6} \mathrm{~kg} / \mathrm{mm}^{3}$

The Velocity of the specimen

$\mathrm{V}_{\mathrm{S}}=3.14 \times 0.025 \times 500$

$=39.25 \mathrm{~m} / \mathrm{s}$

Specific wear rate of rice husk $10 \%$ composite for specimen-1,

$\mathrm{Ws}=0.002 /(0.67 \times 10 \times 300 \times 39.25 \times 5)$

$=0.0510\left(\mathrm{~mm}^{3} / \mathrm{Nm}\right)$

And the wear rate of the specimen-1 is given below

$\mathrm{Wr}=\Delta \mathrm{m} / 2 \Pi . r . n . t$

$=0.002 /(2 \times 3.14 \times 0.0125 \times 500 \times 300)$

$=0.1698 \times 10^{-6} \mathrm{~kg} / \mathrm{mm}^{2}$ 
Table 3: Wear Test Parameters

\begin{tabular}{|c|c|c|c|}
\hline S. No & $\begin{array}{c}\text { Applied Load in } \\
(\mathbf{N})\end{array}$ & Sliding Speed in $(\mathbf{m} / \mathbf{s})$ & Sliding Distance in (m) \\
\hline 1. & 5 & 1 & 500 \\
\hline 2. & 10 & 1 & 500 \\
\hline 3. & 15 & 1 & 500 \\
\hline
\end{tabular}

Table 3 shown above gives the test parameters of the samples used for the wear testing. The samples are tested according to ASTM standards. Three different loads are used for testing and the sliding velocity and the sliding distance are maintained constant. Samples used for testing purposes are of three different compositions such as 10, 20 and 30 per cent of treated and untreated rice husk shall powder mixed with the Polyester resin mixture.

Table 4: Machine Parameters Settings for Wear Test

\begin{tabular}{|l|l|l|l|l|}
\hline S. No & $\begin{array}{r}\text { Sliding } \\
\text { Diameter (mm) }\end{array}$ & Rpm & Time in secs & $\begin{array}{r}\text { Time in } \\
\text { Min: sec }\end{array}$ \\
\hline 1 & 26 & 735 & 500 & 8.332 \\
\hline 2 & 38 & 503 & 500 & 8.332 \\
\hline 3 & 46 & 415 & 500 & 8.332 \\
\hline
\end{tabular}

Table 4 gives the machine parameter settings used for testing purposes. The sliding diameter of the machine is changed for every sample. It is maintained as 26,38 and 46 . Rpm is maintained as 735,503 and 415 for each load in all the three compositions. The running time is maintained to be 8.332 minutes.

Table 5: Weight of Samples Before and After Wear Test

\begin{tabular}{|c|c|c|c|c|c|}
\hline $\begin{array}{c}\text { Initial Weight } \\
\text { in }(\mathrm{g}) \\
5 \mathrm{~N}\end{array}$ & $\begin{array}{l}\text { Final Weight in } \\
(\mathrm{g}) \\
\mathbf{5 N}\end{array}$ & $\begin{array}{c}\text { Initial Weight in } \\
(\mathrm{g}) \\
10 \mathrm{~N}\end{array}$ & $\begin{array}{c}\text { Final Weight in } \\
(\mathrm{g}) \\
10 \mathrm{~N}\end{array}$ & $\begin{array}{c}\text { Initial Weight in } \\
(\mathrm{g}) \\
15 \mathrm{~N}\end{array}$ & $\begin{array}{c}\text { Final Weight in } \\
(\mathrm{g}) \\
15 \mathrm{~N}\end{array}$ \\
\hline 79.347 & 79.213 & 79.213 & 79.207 & 79.207 & 78.945 \\
\hline 69.992 & 69.989 & 69.989 & 69.690 & 69.690 & 69.671 \\
\hline 69.481 & 69.478 & 69.478 & 69.259 & 69.259 & 68.808 \\
\hline
\end{tabular}

Table 5 shows weight of samples before the test and at the end of the test for all the three composite samples. The initial weight and final weights are noted for each sample test specimen. The composites are tested with all the three loads and the wear loss is calculated.

\section{Wear Loss Calculation}

The wear loss calculation is calculated from the initial weight and final value of weight of the specimen after the test is conducted. The wear loss is computed by using the relation,

Wear loss $=($ weight before test - weight at the end of test $) /$ weight before test $* 100$

UT $10 \%$ fiber $5 \mathrm{~N}=(79.347-79.213) / 79.347 * 100$

$=0.1685$

UT $20 \%$ fiber $5 \mathrm{~N}=(79.213-79.207) / 79.213 * 100$

$=0.0075$

UT $30 \%$ fiber $5 \mathrm{~N}=(79.207-78.945) / 79.207 * 100$

$=0.3307$ 
$\mathrm{T} 10 \%$ fiber $5 \mathrm{~N}=(69.992-69.989) / 69.992 * 100$

$=0.0042$

T $20 \%$ fiber $5 \mathrm{~N}=(69.989-69.690) / 69.989 * 100$

$=0.4273$

$\mathrm{T} 30 \%$ fiber $5 \mathrm{~N}=(69.690-69.671) / 69.690 * 100$

$=0.1047$

Results reveal that upon evaluating the wear behaviour, the coefficient of friction value tends to lie between zeros to one. From the results, the minimum coefficient of friction for treated 20 volume $\%$ rice husk powder gives better filler and matrix interaction and results in good interfacial adhesion between filler/matrix and fewer voids in the composite. A high percentage of lignin content in rice husk filler limits filler separation, which leads to less matrix absorption between filler. Steam explosion is the best extraction method for rice husk filler, although an additional mechanically rubbing process is required for filler separation. Generally, high filler content results in good composite performance, but at a certain limit, the matrix does not adhere well with a saturated amount of filler, and the composite wear strength decreases. However, the wear of rice husk powder is not affected by excess filler content.

\section{CONCLUSIONS}

The polyester matrix reinforced with rice husk powder fabricated by hand layup method. The samples are prepared following ASTM standards to perform the Wear test on Pin on Disc equipment. The filler reinforcement percentage is varied as 10\%, 20\% and 30\%.The samples with and without reinforcement are prepared and tested and analysed for wear rate, temperature variation and friction coefficient (COF). It has been identified that when the percentage of rice husk reinforcement increases there is a decrease in COF and hence the temperature variation and wear rate also decreases. But, the effect is maximum at $20 \%$ particle reinforcement as the higher percentage leads to lesser matrix absorption due to agglomeration of particles. Hence, rice husk particles can be effectively employed for the biomaterials subjected to different wear conditions.

\section{REFERENCES}

1. Kandula Mahesh, Bharathiraja, G, Jayakumar, V. Wear analysis of rice husk shell powder reinforced Polyester composite, International Journal of Mechanical and Production Engineering Research and development,9(5),2019,997-1004.

2. Mohd Bilal Naim Shaikh, Sufian Raja, Mukhtar Ahmed, Mohammed Zubair, Adnan Khan, Mohammed Ali, Rice husk ash reinforced aluminium matrix composites: fabrication, characterization, statistical analysis and artificial neural etwork modelling, Materials Research Express,6(5)2019, doi.org/10.1088/2053- $\quad$ 1591/aafbe2.

3. J. Allwyn Kingsly Gladston, I. Dinaharan, N. Mohamed Sheriff, J. David Raja Selvam, Dry sliding wear behaviour of AA6061 aluminium alloy composites reinforced rice husk ash particulates produced using compocasting, Journal of Asian Ceramic Societies, 5( 2) 2017, 127-135.

4. Kuruvilla Joseph, Sherley Annie Paul, Gem Mathew, Laly A. Pothen, and Sabu Thomas, "Preparation of Polypropylene Fibre/Banana Fibre Composites by Novel C Commingling Method”, Polym Compos, 31(5) 2009, 816-824.

5. Murali Mohan Rao, K. and Mohana Rao, K. "Extraction and Tensile Properties of $\quad$ Natural Fibres: Vakka, Date and Bamboo”, J. Compos Struct, 77(2007), 288-295. 
6. Narendra Reddy and Yang Yiqi, "Bio Fibres from Agricultural Byproducts for Industrial Applications”, Trend Bio Technol. 23(2005) 22-27.

7. L. Chang, Z. Zhang, C. Breidt, K. Friedrich, "Tribological properties of Polyester nanocomposites, Enhancement of the wear resistance by nano-TiO2 particles”, Wear, 258(2005),141-148.

8. S. Padma Priya, H. V. Ramakrishna, S. K. Rai, Tensile, Flexural, and Chemical Resistance Properties of Waste Silk Fabricreinforced Polyester Laminates, Journal of reinforced plastics and composites,24(6)2005, 643-648.

9. Hasim Pihtıll, Nihat Tosun, "Effect of load and speed on the wear behaviour of woven glass fabrics and aramid fibrereinforced composites”, Wear, 252(2002), 979-984.

10. Satyanarayana, K.G., Sukumaran, K., Kulkarni, A.G., Pillai S.G.K, Rohatgi, “Performance of Banana Fabric -Polyester Composites”, in Proc. International Conference on Composite Structure, USA, 1983. 